\title{
STRATEGIES TO DEAL WITH GROUND FAULTS IN GRID-CONNECTED TRANSFORMERLESS PHOTOVOLTAIC CONVERTERS WITH BATTERY ENERGY STORAGE SYSTEM
}

\author{
Lucas V. Bellinaso ${ }^{1}$, Ricardo S. Figueredo ${ }^{2}$, Marcelo P. Almeida ${ }^{3}$, Ricardo J. F. Bortolini ${ }^{1}$, Leandro \\ Michels ${ }^{1}$, Ildo Bet ${ }^{2}$, Roberto Zilles ${ }^{3}$ \\ ${ }^{1}$ Power Electronics and Control Group of the Federal University of Santa Maria, Santa Maria, RS, Brazil \\ ${ }^{2}$ PHB Eletrônica LTDA, São Paulo, SP, Brazil \\ ${ }^{3}$ Universidade de São Paulo - USP, São Paulo, SP, Brazil \\ e-mail: lucas@gepoc.ufsm.br, ricardoszf@gmail.com,marcelopa@iee.usp.br, rjochann@gmail.com, michels@gepoc.ufsm.br, \\ ildo@phb.com.br, zilles@usp.br
}

\begin{abstract}
Grid-connected photovoltaic systems with energy storage, also called PV hybrid mini-grid system (PVHMS), operate in both grid-tied and stand-alone modes and are expected to play an important role in distributed generation. Transformerless photovoltaic converters are most preferred for these systems due to their higher conversion efficiency in comparison to insulated converters, increasing autonomy of the battery energy storage system (BESS). Safety in transformerless photovoltaic converters is a critical issue due to parasitic capacitance between PV modules and ground that could result in high leakage current. Existing safety requirements for grid-tied $P V$ inverters may not be sufficient for PVHMS converters since they have multiple leakage current paths. This study analyzes some leakagecurrent-related faults on transformerless PVHMS converters, and proposes relay opening sequences to avoid unnecessary interruptions of power supply for the local loads. The following situations are analyzed: i) fault at de side, ii) fault at ac load side, and iii) commutation between on-grid and off-grid operation modes. These faults have been studied for a transformerless PVHMS converter with a single dc-ac stage. Experimental results are presented to validate the proposed schemes and a table summarizing the proposals is presented.
\end{abstract}

Keywords - Electric shock, Photovoltaic power systems, Power electronics, Protective relaying, Uninterruptible power systems.

\section{INTRODUCTION}

Transformerless bidirectional photovoltaic converters (TPVC) for PV hybrid-mini grid system (PVHMS) [1], [2], have become a trending topic in the last years [3]-[7]. The TPVC integrates photovoltaic (PV) array, battery energy storage system (BESS) and the power grid, and may operate as off-grid inverter, grid-tied inverter or grid rectifier. Due to these operation modes, a TPVC can be understood as the union of grid-tied inverter and uninterruptible power supply (UPS) [8]-[10].

Manuscript received 01/03/2019; first revision 30/04/2019; accepted for publication $03 / 07 / 2019$, by recommendation of Editor Marcello Mezaroba. http://dx.doi.org/10.18618/REP.2019.3.0015
Safety requirements of a PV system are highly dependent on the inverter topology, as stated in IEC 62109-2. Transformerless grid-tied PV inverters may have high common-mode leakage current circulating between PV array and grid due to the parasitic capacitance between PV terminals and ground [11]-[15], which depends on the PV array size, module technology, soiling and humidity [16]. Many transformerless inverter topologies and modulation techniques have been studied to minimize this leakage current [9], [17]-[24], but protection against residual current is always required by IEC $62109-2$ as a preventive measure against fire and shock hazards independently of the topology. When the normal leakage current is lower than $30 \mathrm{~mA} \mathrm{rms}$, the protection may be performed by the application of B-type Residual Current Devices (RCDs), which detects dc and ac currents. However, in some topologies or for high power converters, the normal leakage current may be much higher than the usual $30 \mathrm{~mA}$ rms limit. In these cases, a Residual Current Monitoring Unit (RCMU) with higher continuous residual current limit ( $\geq 300 \mathrm{~mA} \mathrm{rms}$ ) is used for protection. In this case, electric shocks are detected when the residual current suddenly increases by more than $30 \mathrm{~mA}$ rms [25].

During on-grid operation TPVCs have the same residual current protection issues of grid-tied PV inverters, but they are more intricate due to all possible current paths, like the PV array, BESS, different loads, and power grid. For instance, during off-grid mode, the load neutral can be isolated from the ground or connected with high impedance (IT system), or strongly connected to the ground (TN system), as stated in the German standard VDE-AR-E 25102 [26]. This changes the leakage current behavior in off-grid operation. Another issue of TPVCs is the parasitic capacitance between battery terminals and ground [27], which is usually lower than the PV parasitic capacitances, but may compromise the residual current protection of TPVC for residential systems.

Due to the different possible configurations, analyzing leakage current faults in TPVC-based systems becomes a tough task. As shown in [28], several techniques to detect and localize the fault location have been proposed in literature. A comprehensive study of this theme provides technical basis for the development and enhancement of safety standards, as shown in [29], acting procedures in case 
of faults, as well as design guidelines to the industry.

However, after an extensive search in the IEEE, Elsevier and Orbit databases the authors found that the literature only describes the trivial solution to comply with the standards, that is to disconnect all TPVC relays when residual current is detected, turning off the converter.

This manuscript proposes a relay opening sequences for TPVC to keep power supply for loads without compromising the residual current protection. It is proposed an algorithm which considers the location where residual current is detected. The main contribution is to demonstrate that is possible to improve system's availability to supply the loads making TPVC operating in off-grid mode as an IT system. Since neutral grounding is required only for special loads [26], [30], the operation in IT system is not a restriction for most applications. The technique proposed in this paper is executed in the firmware of the converter requiring no additional sensors or switches. Despite being simple, the proposed technique presents advantages in comparison with the trivial solution: i) the fault is detected and isolated without compromising safety; ii) increases reliability of load power supply without increasing hardware cost.

The paper is organized as follows: First, the system is described. Then, the following ground faults are analyzed: i) fault on dc-side in on-grid operation; ii) faults on the ac load side in off-grid operation; and iii) false fault detections when usual RCMUs are used, when the relays should not be opened. Finally, relay opening sequences are proposed for these situations and summarized in a table.

\section{SYSTEM DESCRIPTION}

Assessment of leakage current faults in TPVC-based systems is dependent on the TPVC configurations and topology. In this study, the analyses and discussions of safety issues related to residual current have been performed considering the topology presented in Figure 1. The characteristics (Table II) and a picture (Figure 7.) of the TPVC built are shown in the Appendix. The analyzed TPVC is comprised of a single-phase full-bridge dc-ac converter and two non-isolated dc-dc converters. This topology has been chosen because it is simple, covers most of practical applications and its analysis can be extended to other configurations.

In the topology depicted in Figure 1, the load is connected to the output of the dc-ac converter and the grid is connected to the same node through a bipolar mechanical switch, named here as $\mathrm{S}_{\mathrm{B}}$, which opens during grid outages. The dcac converter may operate as inverter or rectifier depending on the desirable power flow. It is comprised of an H-bridge and 3rd order LCL filters which mitigate the high-frequency content of differential and common mode currents [19]. During on-grid operation, the load neutral conductor $\mathrm{N}^{\prime}$ is connected to the grounded grid neutral conductor $\mathrm{N}$ and the $\mathrm{dc}-\mathrm{ac}$ converter is current-controlled. Otherwise, during offgrid operation, $\mathrm{N}^{\prime}$ is floating as an IT system and the dc-ac converter is voltage-controlled.

A bidirectional dc-dc converter interfaces the battery and the dc bus. For the PV generator, a conventional step-up converter has been employed. More details about the operation of these dc-dc converters can be found in [31], [32].

\section{STRATEGY TO EXTEND OPERATION AFTER A GROUND FAULT AT DC SIDE}

When a dc side fault occurs in an usual transformerless grid-tied PV inverter, usually the residual current increases and the inverter shall disconnect all current-carrying conductors from the grid [33]. The same procedure can be followed when a fault occurs at the dc side of a TPVC. However, a TPVC offers additional features, and the load may continue being supplied in off-grid mode without compromising the residual current protection.

Figure 2.a shows the schematics of a TPVC-based system during a ground fault at the PV array. Ground faults at the PV terminals are more common than those at the battery terminals because the PV array is continuously exposed to the outdoor environment, which is less controllable than the battery environment. A fault at the battery side would have similar results, so it is not demonstrated here. The dc side ground fault has been simulated using the Human Body Model (HBM) [34], [35] in order to limit the maximum current and emulate a touch current. If a sudden increase of $i_{c m A}$ or $i_{c m B}$ is detected during on-grid operation, this means that a fault at the dc side has occurred.

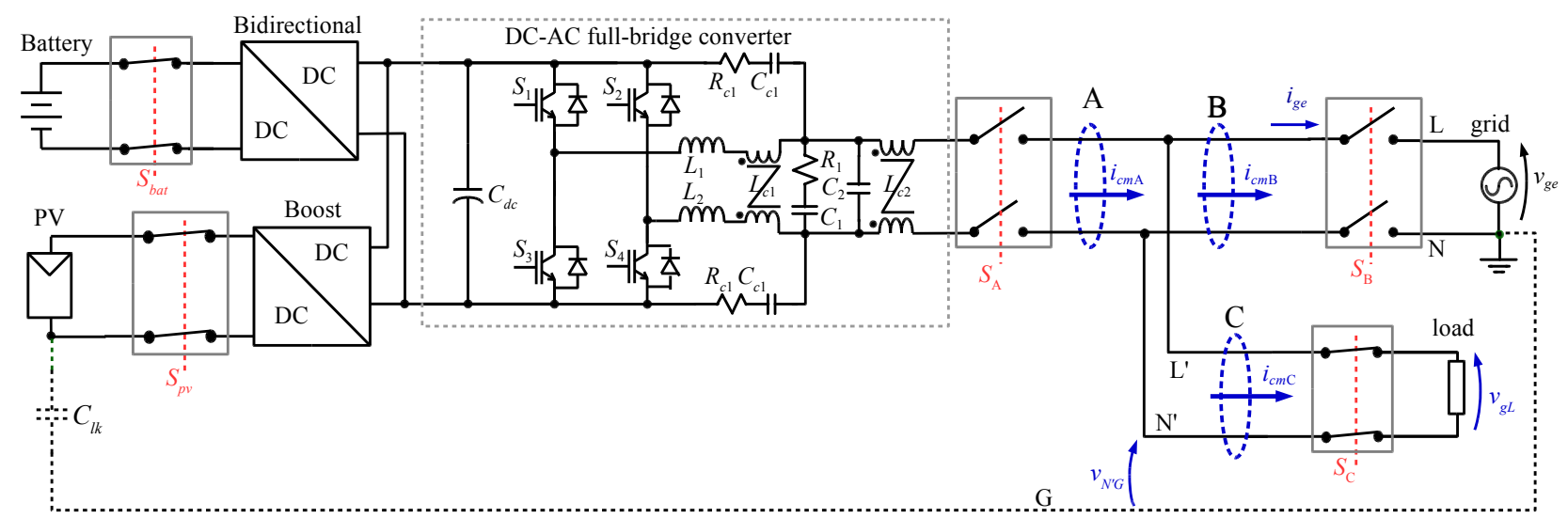

Fig. 1. Diagram of a TPVC with a single dc-ac stage. Its parameters are detailed in the Appendix. 


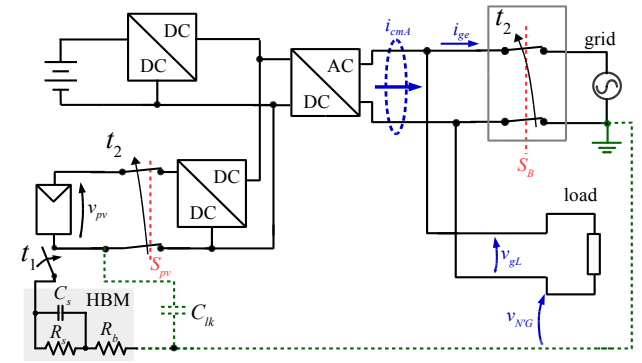

(a)

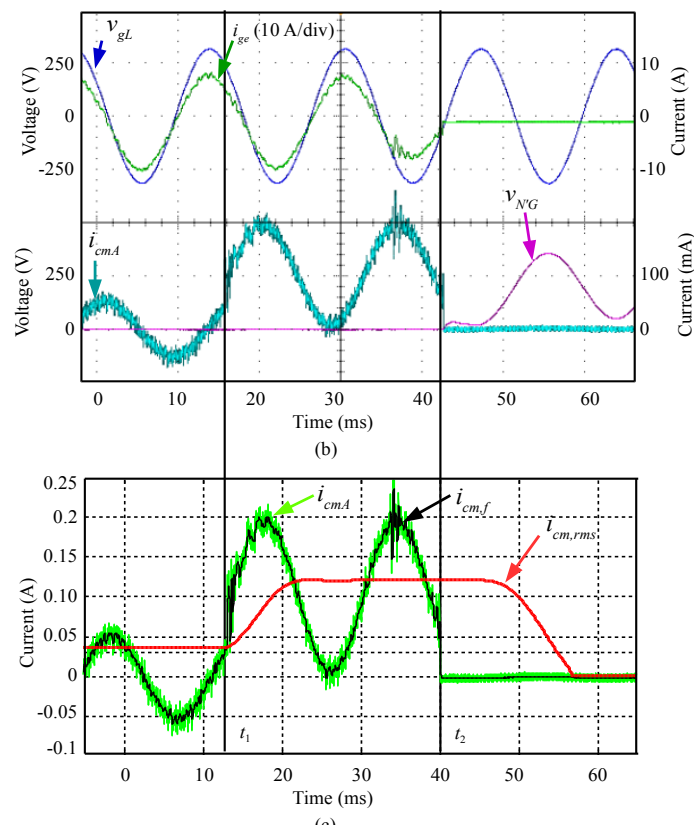

Fig. 2 Strategy to extend operation after a fault at dc side: (a) circuit diagram; (b) Experimental results (voltages and currents); (c) Experimental results - common mode current (measured, filtered and rms value)

Figure 2.b and Figure 2.c show experimental results of voltage and currents illustrated in the case shown in Figure 2.a, where the load supply voltage is given by $v_{g L}$. The system initially operates in on-grid mode. At $t_{1}$, a ground fault at the PV side occurs, and the rms value of the common mode current suddenly increases from $40 \mathrm{~mA}$ rms to $120 \mathrm{~mA}$ rms. The grid is then disconnected at $t_{2}$ and the residual current is eliminated. The PV array is also disconnected, and the load continues being supplied $\left(v_{g L}\right)$ by the BESS power without compromising the residual current protection.

The following troubleshooting procedures are proposed when a fault is detected during grid-tied operation:

1) Main protection: switch off the grid $\left(S_{B}\right)$, then the $P V$ array $\left(\mathrm{S}_{\mathrm{PV}}\right)$.

After switching off $\mathrm{S}_{\mathrm{B}}$, the residual current is probably eliminated. It is also recommended to switch off the poles of the PV array supposing that most dc faults may happen at the PV side due to ambient exposure. The load continues being supplied by the BESS and the fault is probably isolated from the other parts of the system. In case the dc fault is not at the PV side, this procedure does not isolate the fault. This possibility can be verified by detecting the ground insulation resistance at the battery connection terminals, whose requirements are specified in IEC 62109-2.

2) Back-up protection: switch off the remaining switches and it indicates a fault.

In case the residual current persists, this means the fault has not occurred at the PV side or the system has another problem. Therefore, it is recommended to turn the TPVC off and open all system relays. Main and back-up protections must be done within the maximum RCMU operation time.

It is important to notice that, if a dc fault is caused at the battery side, the battery can be disconnected after the grid disconnection, and the load could be theoretically supplied by the PV generator. However, the PV generator usually provides intermittent power, so it is not possible to rely on PV power to supply the loads. Thus, after assuring battery disconnection by measuring insulation resistance, the grid could be reconnected to supply the load.

Ground faults at the de side may also occur during offgrid operation. This fault may be detected as an increment of currents $\mathrm{i}_{\mathrm{cmA}}$ or $\mathrm{i}_{\mathrm{cmC}}$ if the loads have high parasitic capacitance to ground, or by measuring the insulation resistance to ground. In this case, it is recommended to disconnect the PV system $\left(\mathrm{S}_{\mathrm{PV}}\right)$ as main protection and disconnect other switches as back-up protection if the residual current persists. Moreover, if residual current is below the protection limits but the insulation resistance is below the minimum required in IEC $62109-2$, the TPVC shall not connect to the grid. In all cases, the fault must be signaled.

\section{STRATEGY TO AVOID FALSE RESIDUAL CURRENT FAULT DETECTIONS DURING OPERATION MODE COMMUTATIONS}

Leakage current path is closed during on-grid operation and opened when off-grid. False residual current fault detections may occur if the residual current suddenly increases by more than $30 \mathrm{~mA}$ during transfers between offgrid and grid-tied operation modes. RCMUs that comply with IEC 62109-2 would disconnect from the grid and indicate a fault whenever a sudden residual current increase higher than $30 \mathrm{~mA}$ rms occurs. For TPVC-based systems, a fast transfer from off-grid to grid-tied operation may suddenly increase the measured residual current by more than $30 \mathrm{~mA} \mathrm{rms}$, so this normal situation would be wrongly identified as a fault.

A modified RCMU rule shall be used for proper system functioning. The residual current monitoring shall consider the sudden changes of residual current as inherent to the grid connection or disconnection process, and not a fault. One possible solution is to disable the residual current protection when the TPVC is connecting to the grid, during the closure of switch $\mathrm{S}_{\mathrm{B}}$.

Experimental results showing the TPVC connection/disconnection to/from the grid are shown in Figure 3.a and Figure 3.b. The connection to the grid occurs at instant $t_{1}$, when switch $S_{B}$ is closed. In this moment, the rms leakage current $i_{\mathrm{cm}, \text { rms }}$ suddenly increases from zero to above $30 \mathrm{~mA} \mathrm{rms}$, where $i_{\mathrm{cm}, \mathrm{rms}}$ can be detected at A or B of Figure 1. If a usual RCMU were used, the system would detect a fault and immediately disconnect from the grid. However, this sudden increase shall be considered a normal event, and not a fault. In the experimental result of Figure 3, 


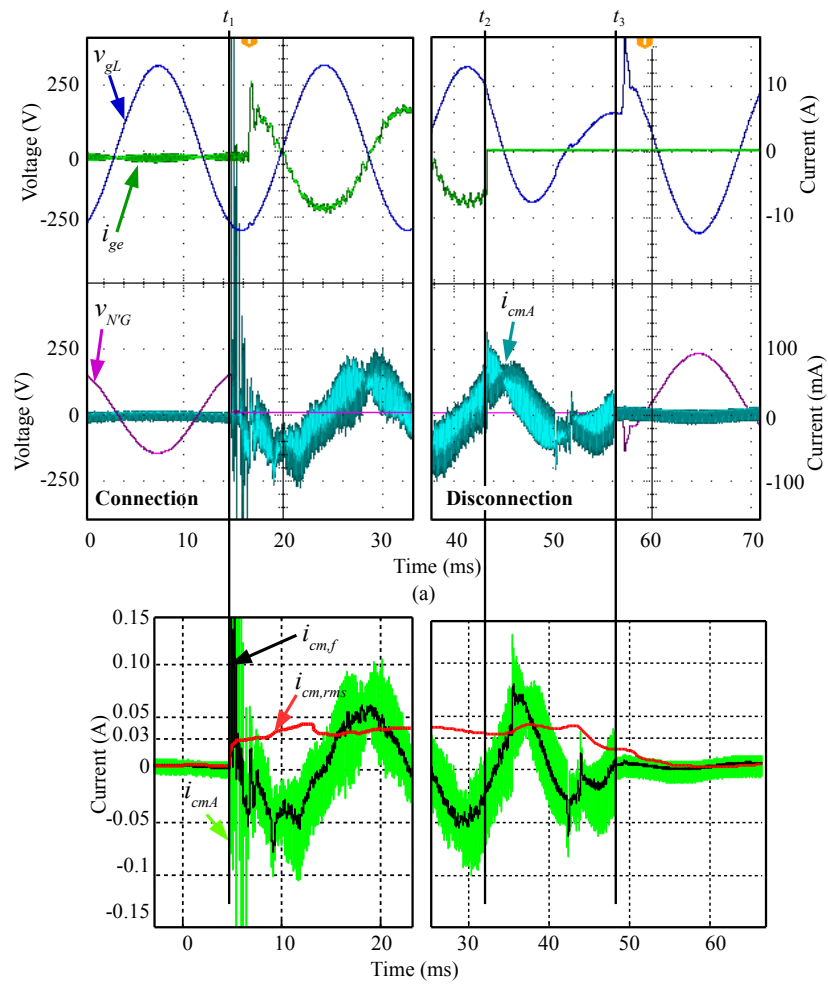

(b)

Fig. 3 Residual current detections during operation mode commutations: (a) Experimental results (voltages and currents); (b) Experimental results - common mode current (measured, filtered and rms value).

the residual current protection was disabled, so connection occurred correctly.

In Figure 3.a, when the TPVC begins to disconnect from the grid at instant $t_{2}$, the output current $i_{\text {ge }}$ is set to zero, but the leakage current is still around $40 \mathrm{~mA} \mathrm{rms}$. At instant $\mathrm{t}_{3}$, the TPVC is completely disconnected from the grid and the leakage current instantly becomes zero. A usual RCMU would not consider this as a fault, because the leakage current reduces instead of increasing, so it is not necessary to disable the RCMU protection during grid disconnection.

It's important to notice that, if the TPVC works as a TN system when off-grid, a relay would connect $N$ ' to the ground soon after complete grid disconnection. The same way as the connection to the grid, this would cause a sudden residual current change and should be detected as a false residual current detection.

\section{STRATEGY TO EXTEND OPERATION AFTER A GROUND FAULT AT THE LOAD SIDE}

Ground faults at the load side may happen during on-grid and off-grid operation. When the TPVC shown in Figure 1 is connected to the grid, a ground fault at the ac load can be detected measuring suddenly changes in currents $\mathrm{i}_{\mathrm{cmB}}$ and $\mathrm{i}_{\mathrm{cmC}}$. In this case, it is recommended to disconnect $\mathrm{S}_{\mathrm{B}}$ and start off-grid operation as main protection. If the residual current persists, the other switches can be disconnected as back-up protection

During off-grid operation, the ac load side operates as an IT system because there is no neutral grounding. However, due to the ground fault at load side, the residual current through the parasitic capacitance of the PV array may be higher than the safety limit of $30 \mathrm{~mA} \mathrm{rms}$. Therefore, a protection against residual current at the load side is mandatory even when the TPVC operates off-grid.

One first solution to protect against residual current during off-grid operation is to install a $30 \mathrm{~mA} \mathrm{RCD}$ at the ac load output. Figure 4.a shows the schematics of this possibility. Figure 4.b and Figure 4.c shows experimental results using a $30 \mathrm{~mA} \mathrm{rms} \mathrm{RCD}$. At instant $\mathrm{t}_{1}$, a short-circuit from the load neutral (N') to ground $(\mathrm{G})$ was emulated by closing an external switch, the residual current measured at point $\mathrm{A}$ suddenly increased to about $40 \mathrm{~mA}$ rms. As long as a usual $\mathrm{RCD}$ was installed, this RCD opens at instant $t_{2}$, interrupting both the fault and the load power supply.

The proposed solution is not to use a usual RCD, but to monitor the current at $\mathrm{i}_{\mathrm{cmC}}\left(\right.$ or $\left.\mathrm{i}_{\mathrm{cmA}}\right)$ and open the PV switch, avoiding unnecessary load power supply interruption. If the leakage current is detected at $\mathrm{i}_{\mathrm{cmc}}$ or $\mathrm{i}_{\mathrm{cmA}}$ during off-grid operation, the following relay opening sequence is proposed:

1) Main protection: switch off the PV array $\left(\mathrm{S}_{\mathrm{PV}}\right)$

Considering that most of detected residual current comes from the PV array, the PV array can be initially disconnected to avoid premature load disconnection.

2) Back-up protection: turn off the remaining switches.

In case the residual current persists, this means most of residual current does not come from the PV array or the

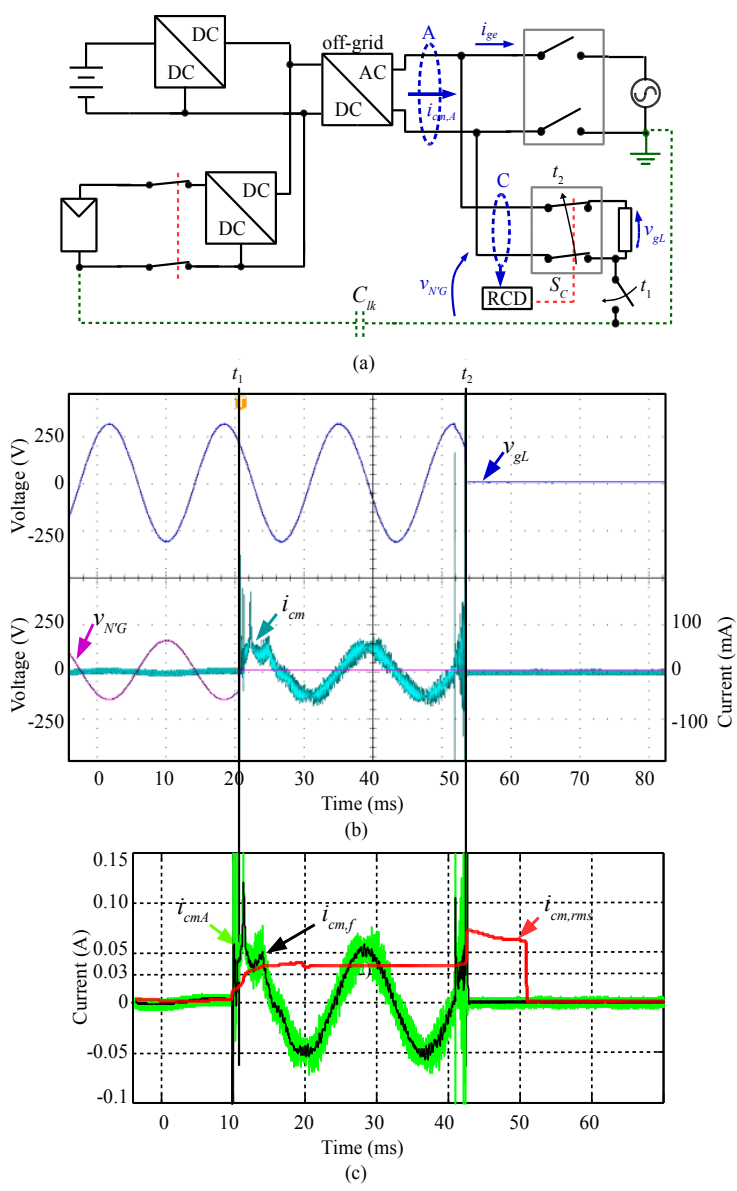

Fig. 4 Fault at ac side during off-grid operation - protection by RCD: (a) circuit diagram; (b) Experimental results (voltages and currents); (c) Experimental results - common mode current (measured, filtered and rms value). 
system has another problem. Therefore, it is necessary to disconnect the loads and then all system relays.

Experimental results have been performed to demonstrate the proposed solution. A fault between load neutral and ground during off-grid operation was emulated using a switch closed at instant $t_{1}$, as shown in the schematic of Figure 5.a. The neutral voltage to ground and load voltage are shown in Figure 5.b, and the residual current is shown in Figure 5.c. After the fault is applied at instant $t_{1}$, the rms residual current value rises above $30 \mathrm{~mA}$ rms. The main protection is applied at instant $t_{2}$ by disconnecting the PV array. As long as the residual current is due to the PV parasitic capacitance, the residual current is eliminated after this disconnection. Therefore, the load continues being supplied by the BESS, as indicated by load voltage $\mathrm{v}_{\mathrm{gL}}$. After the fault is detected, it is necessary to indicate the fault to the user, as required in IEC 62109-2. The interval between the ground fault $\left(\mathrm{t}_{1}\right)$ and the disconnection of the PV array $\left(\mathrm{t}_{2}\right)$ is around $40 \mathrm{~ms}$, which is lower than the maximum allowed time considered in IEC 62109-2 (150 ms for $60 \mathrm{~mA} \mathrm{rms})$.
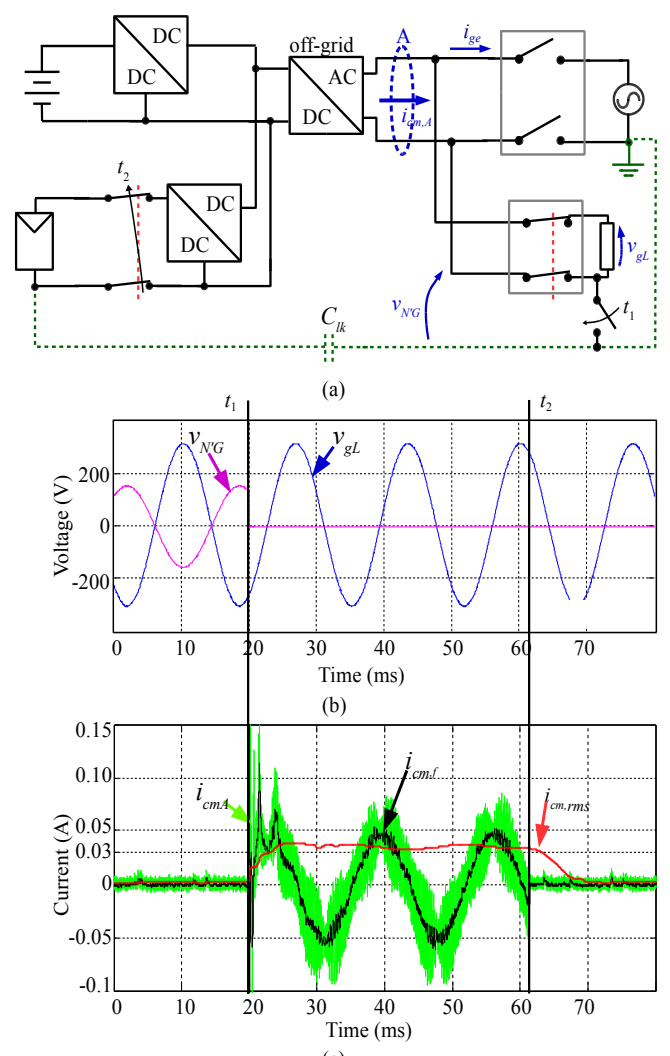

(c)

Fig. 5 Fault at ac side during off-grid operation - proposed protection strategy: (a) circuit diagram; (b) Experimental results (voltages and currents); (c) Experimental results - common mode current (measured, filtered and rms value).

\section{SUMMARY OF PROPOSED STRATEGIES}

Table I summarizes the proposed strategies. Depending on the operation mode and the place where residual current is detected, different relay operation sequences are adopted as shown in the flow chart of Figure 6. These sequences have been chosen to avoid load disconnection whenever possible. It is important to notice that the main and back-up protection shall act within the intervals presented in IEC 62109-2 to ensure compliance to safety standards.

It is also important to note that the dc side fault (Case 2) and load side fault with low $\mathrm{C}_{\mathrm{lk}}$ (Case $4 \mathrm{~b}$ ) both in off-grid mode cannot be detected by residual current detection, but by low ground insulation resistance $\left(\mathrm{R}_{\text {iso }}\right)$. During normal offgrid operation, $\mathrm{R}_{\text {iso }}$ shall be high because the system is isolated from the ground. However, this resistance becomes low when any fault to ground occurs. Load side fault in offgrid mode cannot be detected by residual current detection if $\mathrm{C}_{\mathrm{lk}}$ is low, but only by low insulation resistance $\left(\mathrm{R}_{\mathrm{iso}}\right)$. During normal off-grid operation, $\mathrm{R}_{\text {iso }}$ shall be high because the system is isolated from the ground. However, this resistance becomes low when any fault to ground occurs.

\section{CONCLUSION}

This study proposes relay opening sequences for some ground faults of TPVC in PVHMS in order to avoid unnecessary load disconnection, maintaining the UPS functionality. Experimental results have been presented to illustrate these proposals. It has been shown that load can be continuously supplied by the BESS after ground faults at the PV side or even at the load side by disconnecting only the grid and/or the PV generator. It has been also demonstrated that normal transfer from off-grid to on-grid operation mode can cause false residual current fault detection. It is also demonstrated that the simplest solution to avoid the false detection is to ignore this protection during a short period before and after the connection of the converter to the grid. It's important to note that although the power of the prototype used to test the concepts is $1500 \mathrm{~W}$, inverter power is not a limitation to the applicability of the techniques proposed in this paper.

The importance of this study is to provide new procedures and design guidelines for TPVC which improve their performance without harming user safety. Further studies in this field can consider other topologies of TPVC systems and the presence of galvanic isolation between PV generator, BESS, load and grid.

\section{ACKNOWLEDGMENT}

The author thanks the INCTGD, CAPES, CNPq and FAPERGS for the financial support received for the development of this work. The present work was carried out with the support of INCT and its funding agencies $(\mathrm{CNPq}$ process 465640 / 2014-1, CAPES process No. 23038.000776 / 2017-54 and FAPERGS 17 / 2551-0000517-1).

This study was financed in part by the Coordenação de Aperfeiçoamento de Pessoal de Nível Superior - Brasil (CAPES) - Finance Code 001 
TABLE I

Summary of Residual Current Detection and Relay Opening Sequence

\begin{tabular}{|c|c|c|c|c|c|c|c|c|}
\hline \multirow{2}{*}{ Case } & \multirow{2}{*}{$\begin{array}{l}\text { Fault (to } \\
\text { ground) } \\
\text { location }\end{array}$} & \multirow{2}{*}{ Mode } & \multirow{2}{*}{$\begin{array}{c}\boldsymbol{R}_{\text {iso }} \\
\text { detection }\end{array}$} & \multicolumn{3}{|c|}{$\begin{array}{c}\text { Residual } \\
\text { Current detection }\end{array}$} & \multicolumn{2}{|c|}{ Relay opening sequence ${ }^{1}$} \\
\hline & & & & $i_{c m A}$ & $i_{c m B}$ & $i_{c m C}$ & Main protection & $\begin{array}{c}\text { Back-up } \\
\text { protection }^{2}\end{array}$ \\
\hline 1 & DC side & On-grid & - & true & true & false & $\begin{array}{c}S_{B} \rightarrow S_{p v}, \text { alarm } \\
\text { Go to fault } 2 .^{3}\end{array}$ & $S_{A}, S_{\mathrm{C}}, S_{b a t}$ \\
\hline 2 & DC $\operatorname{side}^{4}$ & Off-grid & low & $\underset{4}{\text { false }}$ & false & $\underset{4}{\text { false }}$ & alarm & $S_{A}, S_{B}, S_{C}, S_{p v}, S_{b a t}$ \\
\hline 3 & Load side & On-grid & - & false & true & true & $\begin{array}{c}S_{B} \text {, alarm } \\
\text { Go to fault } 4 \mathrm{a} \text { or } 4 \mathrm{~b} .^{3}\end{array}$ & $S_{p v}, S_{C}, S_{A}, S_{b a t}$ \\
\hline $4 a$ & $\begin{array}{l}\text { Load side (if } C_{l k} \\
\text { is } \text { high }^{5} \text { ) }\end{array}$ & Off-grid & low & true & false & true & $S_{p v}$, alarm & $S_{C} \rightarrow S_{A}, S_{B}, S_{b a t}$ \\
\hline $4 b$ & $\begin{array}{l}\text { Load side (if } C_{l k} \\
\text { is low }{ }^{5} \text { ) }\end{array}$ & Off-grid & low & false & false & false & alarm & $S_{p v}, S_{C}, S_{A}, S_{B}, S_{b a t}$ \\
\hline 5 & $\begin{array}{c}\text { Grid connection } \\
\text { (false residual } \\
\text { current } \\
\text { detection) }\end{array}$ & $\begin{array}{l}\text { Off-grid } \\
\text { to On- } \\
\text { grid }\end{array}$ & - & true & true & false & \multicolumn{2}{|c|}{ Residual current protection shall be blocked } \\
\hline
\end{tabular}

${ }^{1}$ The arrow $(\rightarrow)$ means a consecutive operation, while the comma $($,) means a simultaneous operation.

${ }^{2}$ Only if the main protection fails or a residual current continues being detected.

${ }^{3}$ After disconnecting SB, the system starts off-grid operation.

${ }^{4}$ Assuming that load parasitic capacitances are insignificant.

${ }^{5}$ High Clk means that the nominal leakage current of (1) is higher than $30 \mathrm{mArms}$, while low Clk means a lower leakage current.

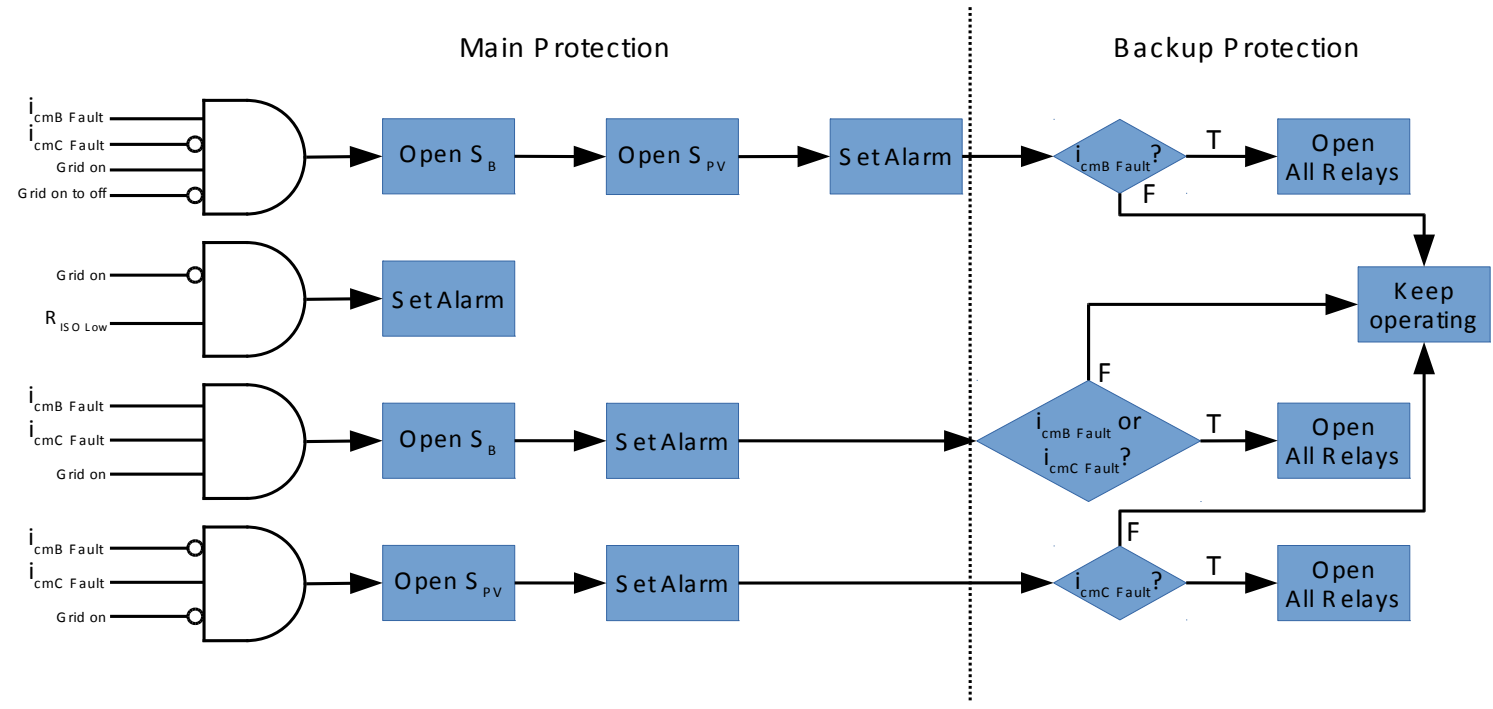

Fig. 6 Flow chart of the fault detection and relay opening sequence.

\section{APPENDIX}

Table II shows the parameters of the prototype implemented to obtain the experimental results, as shown in Figure 1.

TABLE II

System Parameters

\begin{tabular}{ll}
\hline \multicolumn{1}{c}{ Parameter } & \multicolumn{1}{c}{ Description } \\
\hline$C_{d c}=2500 \mu \mathrm{F}$ & $\mathrm{dc}$ bus capacitance \\
$L_{1}=L_{2}=400 \mu \mathrm{H}$ & $\mathrm{dc}$-ac converter main inductors \\
$L_{c 1}=8 \mathrm{mH}$ & $\mathrm{dc}$-ac converter main common-mode inductor \\
$L_{c 2}=1,3 \mathrm{mH}$ & $\mathrm{dc}-\mathrm{ac}$ converter $2^{\text {nd }}$ common-mode inductor \\
$C_{c 1}, C_{c 2}=2 \mu \mathrm{F}$ & $\mathrm{dc}-\mathrm{ac}$ converter common-mode filter capacitances \\
$R_{c 1}, R_{c 2}=10 \Omega$ & $\mathrm{dc}-\mathrm{ac}$ converter common-mode filter resistor \\
$C_{1}=C_{2}=5 \mu \mathrm{F}$ & $\mathrm{dc}-\mathrm{ac}$ converter output capacitance \\
$R_{1}=2 \Omega$ & $\mathrm{dc}-\mathrm{ac}$ converter damping resistance
\end{tabular}

$$
\begin{array}{ll}
C_{l k}=1 \mu \mathrm{F} & \text { PV generator parasitic capacitance } \\
v_{g e}=v_{g L}=220 \mathrm{~V} & \text { ac grid and load nominal rms voltage } \\
v_{d c}=400 \mathrm{~V} & \text { dc bus voltage } \\
v_{b a t}=48 \mathrm{~V} & \text { Battery nominal voltage } \\
v_{p v}=200 \mathrm{~V} & \text { PV nominal voltage at maximum power point } \\
v_{p v, o c}=250 \mathrm{~V} & \text { PV nominal open circuit voltage } \\
f_{s w 1}=24 \mathrm{kHz} & \text { dc-ac converter switching frequency } \\
f_{s w 2}=48 \mathrm{kHz} & \text { dc-dc converters switching frequency } \\
P_{a c}=1500 \mathrm{~W} & \text { ac load and dc-ac converter nominal power }
\end{array}
$$




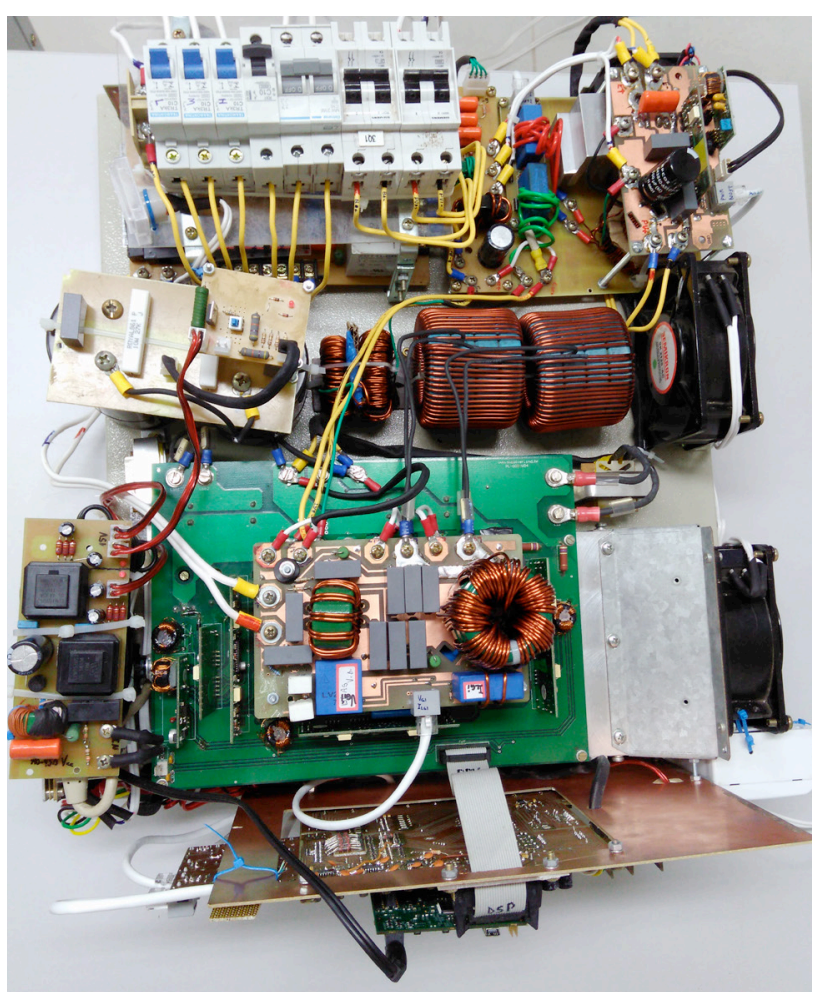

Fig. 7 Picture of the $1500 \mathrm{~W}$ prototype implemented

\section{REFERENCES}

G. Léna, Rural Electrification with PV Hybrid Systems. 2013.

[2] J. Hazelton, A. Bruce, and I. MacGill, "A review of the potential benefits and risks of photovoltaic hybrid mini-grid systems", in Renew. Energy, vol. 67, p. 222-229, 2014

[3] F. Harirchi, M. G. Simoes, M. Babakmehr, A. AlDurra, S. M. Muyeen, and A. Bubshait, "Multifunctional double mode inverter for power quality enhancement in smart-grid applications", in IEEE Industry Applications Society Annual Meeting, p. 18, 2016.

[4] E. Ozdemir and F. Kavaslar, "A new multifunctional power converter for grid connected residential photovoltaic applications", in IEEE Energy Conversion Congress and Exposition, p. 2650-2656, September 2009.

[5] N. Sasidharan and J. G. Singh, "A Novel SingleStage Single-Phase Reconfigurable Inverter Topology for a Solar Powered Hybrid AC/DC Home", in IEEE Trans. Ind. Electron., vol. 64, no. 4, p. 2820-2828, Apr. 2017.

[6] P. V. Subramanyam and C. Vyjayanthi, "Integration of PV and battery system to the grid with power quality improvement features using bidirectional AC-DC converter," in International Conference on Electrical Power and Energy Systems (ICEPES), no. Cv, p. 127-132, 2016.

[7] L. Bellinaso and L. Michels, "Multifunctional Photovoltaic Converters - Classification And Requirements For Grid And Load Compatibility", in
Eletrônica de Potência, vol. 21, no. 2, p. 126-137, May 2016

[8] R. J. F. Bortolini, L. Michels, L. V. Belinaso, and J. R. Massing, "Compatibilizing multifunctional photovoltaic converters with Brazilian standards: Analysis and discussion", in 14th Brazilian Power Electron. Conf. COBEP 2017, vol. 2018, p. 1-6, Jan. 2018.

[9] Y. Tang, W. Yao, P. C. Loh, and F. Blaabjerg, "Highly Reliable Transformerless Photovoltaic Inverters with Leakage Current and Pulsating Power Elimination", in IEEE Trans. Ind. Electron., vol. 63, no. 2, p. 1016-1026, February 2016.

[10] S. Karve, "Three of a kind", in IEEE Rev., pp. 27 32, March 2000.

[11] C. A. Charalambous, A. Demetriou, and N. D. Kokkinos, "Impact of Photovoltaic-Oriented DC Stray Current Corrosion on Large-Scale Solar Farms' Grounding and Third-Party Infrastructure: Modeling and Assessment", in IEEE Trans. Ind. Appl., vol. 51, no. 6, p. 5421-5430, Nov. 2015.

[12] B. Gu, J. Dominic, J. S. Lai, C. L. Chen, T. Labella, and B. Chen, "High reliability and efficiency singlephase transformerless inverter for grid-connected photovoltaic systems", in IEEE Trans. Power Electron., vol. 28, no. 5, p. 2235-2245, May 2013.

[13] T. Kerekes, D. Sera, and L. Mathe, "Leakage current measurement in transformerless PV inverters", in Proc. Int. Conf. Optim. Electr. Electron. Equipment, OPTIM, p. 887-892, May 2012.

[14] J. M. A. Myrzik and M. Calais, "String and module integrated inverters for single-phase grid connected photovoltaic systems - A review", in IEEE Bol. PowerTech - Conf. Proc., vol. 2, p. 430-437, June 2003.

[15] SMA, "Technical Information Capacitive Leakage Currents," 2015.

[16] M. Calais, V. G. Agelidis, and M. Meinhardt, "Multilevel converters for single-phase grid connected photovoltaic systems: an overview", in Sol. Energy, vol. 66, no. 5, p. 325-335, Aug. 1999.

[17] W. Li, Y. Gu, H. Luo, W. Cui, X. He, and C. Xia, "Topology review and derivation methodology of single-phase transformerless photovoltaic inverters for leakage current suppression", in IEEE Trans. Ind. Electron., vol. 62, no. 7, p. 4537-4551, February 2015.

[18] S. Jain and V. Sonti, "A Highly Efficient and Reliable Inverter Configuration Based Cascaded Multilevel Inverter for PV Systems", in IEEE Trans. Ind. Electron., vol. 64, no. 4, p. 2865-2875, Apr. 2017.

[19] R. S. Figueredo, K. C. M. de Carvalho, N. R. N. Ama, and L. Matakas, "Leakage current minimization techniques for single-phase transformerless grid-connected PV inverters - An overview", in Brazilian Power Electronics Conference, p. 517-524, 2013.

[20] N. Vazquez, M. Rosas, C. Hernandez, E. Vazquez, and F. J. Perez-Pinal, "A new common-mode 
transformerless photovoltaic inverter", in IEEE Trans. Ind. Electron., vol. 62, no. 10, p. 6381-6391, April 2015.

[21] R.-T. Li, C. N. M. Ho, and E.-X. Chen, "Active Virtual Ground - Single Phase Transformerless GridConnected Voltage Source Inverter Topology", in IEEE Trans. Power Electron., vol. 33, no. 2, p. 1-1, March 2017.

[22] J. Giacomini, L. Michels, H. Pinheiro, and C. Rech, "Active Damping Scheme for Leakage Current Reduction in Transformerless Three-phase Gridconnected PV Inverters", in IEEE Trans. Power Electron., vol. 33, no. 5, p. 1-1, June 2017.

[23] X. Guo, R. He, J. Jian, Z. Lu, X. Sun, and J. M. Guerrero, "Leakage current elimination of four-leg inverter for transformerless three-phase PV systems", in IEEE Trans. Power Electron., vol. 31, no. 3, p. 1841-1846, March 2016.

[24] L. Wang, Y. Shi, Y. Shi, R. Xie, and H. Li, "Ground Leakage Current Analysis and Suppression in a 60kW 5-Level T-Type Transformerless SiC PV Inverter", in IEEE Trans. Power Electron., vol. 33, no. 2, p. 1271-1283, February 2018.

[25] J. C. Hernandez, P. G. Vidal, and F. Jurado, "Guidelines to requirements for protection against electric shock in PV generators", in IEEE Power Engineering Society General Meeting, p. 576-581, June 2005.

[26] VDE, "Stationary Electrical Energy Storage Systems intended for Connection to the Low Voltage Grid", in VDE-AR-E 2510-2, 2015.

[27] A. Ginart, A. Salazar, and R. Liou, "Transformerless Bidirectional Inverter for Residential Battery Storage Systems", in IEEE Green Technol. Conf., p. 18-23, April 2016.

[28] S. R. Madeti and S. N. Singh, "A comprehensive study on different types of faults and detection techniques for solar photovoltaic system", in Sol. Energy, vol. 158, p. 161-185, Dec. 2017.

[29] J. Flicker and J. Johnson, "Photovoltaic ground fault detection recommendations for array safety and operation", in Sol. Energy, vol. 140, p. 34-50, Dec. 2016.

[30] B. Li, Y. Li, and T. Ma, "Research on earthing schemes in LV microgrids", in International Conference on Advanced Power System Automation and Protection, p. 1003-1007, 2011.

[31] R. W. Erickson, Fundamentals of Power Electronics. Secaucus, NJ, USA: Kluwer Academic Publishers, 2000.

[32] C. D. Schwertner, L. V. Bellinaso, H. L. Hey, and L. Michels, "Supervisory control for stand-alone photovoltaic systems", in Brazilian Power Electron. Conf., p. 582-588, Oct. 2013.

[33] International Electrotechnical Commission, "Safety of power converters for use in photovoltaic power systems. Part 2 - Particular requirements for inverters", in IEC 62109-2, 2011.

[34] International Electrotechnical Commission, "Safety of power converters for use in photovoltaic power systems. Part 1 - General Requirements", in IEC 62109-1, 2010.

[35] International Electrotechnical Commission, "Methods of measurement of touch current and protective conductor current", in IEC 60990, 2016.

\section{BIOGRAPHIES}

Lucas V. Bellinaso, received the B.S. and M.S. degrees in electrical engineering, in 2012 and the M.Sc. and $\mathrm{PhD}$ degrees in electrical engineering from the Federal University of Santa Maria (UFSM), Santa Maria, Brazil, in 2014 and 2017, respectively. Since 2015, he has been with the Power Electronics and Control Group (GEPOC) at the same university, where he is currently Professor. His research interests are PV systems, applied digital control, and power management of microgrids.

Ricardo S. Figueredo, Ricardo Souza Figueredo received the B.S. degree in electrical engineering from the Pontifical Catholic University of Sao Paulo, São Paulo, Brazil, in 2010 and the M.S. degree in electrical engineering from the Polytechnic School of the University of São Paulo, São Paulo, Brazil, in 2015. His current research interests include design and modelling of power converters for renewable energy sources and digital control of power converters.

Marcelo P. Almeida, was born in Belém, Brazil, in 1987. He received the B.Eng. degree in Electrical Engineering from the Federal University of Pará (UFPA), Brazil, in 2009, the M.Sc. degree in Energy from the University of São Paulo (USP), Brazil, in 2012, and the D.Sc. degree in Energy in 2017, also from USP. He is a researcher at the Photovoltaic Systems Laboratory (LSF) of the Institute of Energy and Environment of the University of São Paulo (LSF-IEE-USP), the vice president of the Brazilian Solar Energy Association (ABENS), a board member of the International Solar Energy Society (ISES) and a reviewer of Solar Energy and Progress in Photovoltaics: Research and Applications journals.

Ricardo J. F. Bortolini, was born in Rodeio Bonito, Brazil, in 1992. He received the B.S degree in Automatic Control and Systems Engineering and M.Sc. degree in Electrical Engineering from the Federal University of Santa Maria (UFSM), Brazil in 2015 and 2018, respectively. He is currently a Ph.D. student and substitute technical manager of the UFSM's PV inverters tests laboratory and is member of working groups that develops Brazilian's PV standards. His current research interests include PV systems and in field measurements of PV systems.

Leandro Michels, received the B.S and Ph.D. degrees in Electrical Engineering from Federal University of Santa Maria (UFSM), Brazil, in 2002 and 2006, respectively. He is currently an Associate Professor at the UFSM working with the Power Electronics and Control Research Group (GEPOC) and has a research grant level DT-1D from National Council for Scientific and Technological Development (CNPq-Brazil). Dr. Michels is the manager of UFSM's PV inverters tests laboratory and is member of 
working groups that develops Brazilian's PV standards. His current research interests include PV systems and applied digital control.

Ildo Bet, Founding partner and director of engineering of PHB Eletrônica Ltda since 1984 in the city of São Paulo. He holds a degree in Electrical Engineering from PUC-RS (1978) and a Master's degree in Power Electronics from INEP / UFSC (1981). He is the director of ABINEE's Photovoltaic Sector Group and is coordinator of ABNT / COBEI / CE03: 82.01 - Photovoltaic Systems Studies Committee, focusing on Brazilian technical standards for photovoltaic inverters connected to the grid.
Roberto Zilles, Roberto Zilles was born in Novo Hamburgo, Rio Grande do Sul, Brazil, in 1960. He received the B.S. degree in Physics from the Federal University of Rio Grande do Norte (UFRN), Brazil, in 1985, and M.S. degree in mechanical engineering from the Federal University of Rio Grande do Sul (UFRGS), Brazil, in 1988, and the Dr. Ing. degree from the Polytechnic University of Madrid, Spain, in 1993. He founded the Photovoltaic System Laboratory from the Institute of Energy and Environment of the São Paulo University (LSF-IEE-USP) in 1995. Prof. Zilles, since 1998, is member of editorial board of the Progress in Photovoltaics: Research and Applications journal 